\title{
Cytogenetics and stripe rust resistance of wheat-Thinopyrum elongatum hybrid derivatives
}

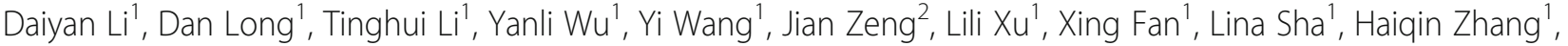 \\ Yonghong Zhou' ${ }^{1}$ and Houyang Kang ${ }^{\text {* }}$
}

\begin{abstract}
Background: Amphidiploids generated by distant hybridization are commonly used as genetic bridge to transfer desirable genes from wild wheat species into cultivated wheat. This method is typically used to enhance the resistance of wheat to biotic or abiotic stresses, and to increase crop yield and quality. Tetraploid Thinopyrum elongatum exhibits strong adaptability, resistance to stripe rust and Fusarium head blight, and tolerance to salt, drought, and cold.

Results: In the present study, we produced hybrid derivatives by crossing and backcrossing the Triticum durum-Th. elongatum partial amphidiploid (Trititrigia 8801, $2 n=6 x=42$, AABBEE) with wheat cultivars common to the Sichuan Basin. By means of cytogenetic and disease resistance analyses, we identified progeny harboring alien chromosomes and measured their resistance to stripe rust. Hybrid progenies possessed chromosome numbers ranging from 40 to 47 (mean $=42.72$ ), with $40.0 \%$ possessing 42 chromosomes. Genomic in situ hybridization revealed that the number of alien chromosomes ranged from 1 to 11 . Out of the 50 of analyzed lines, five represented chromosome addition $(2 n=44=42 \mathrm{~W}+2 \mathrm{E})$ and other five were chromosome substitution lines $(2 n=$ $42=40 \mathrm{~W}+2 \mathrm{E})$. Importantly, a single chromosome derived from wheat-Th. elongatum intergenomic Robertsonian translocations chromosome was occurred in 12 lines. Compared with the wheat parental cultivars ('CN16' and 'SM482'), the majority (70\%) of the derivative lines were highly resistant to strains of stripe rust pathogen known to be prevalent in China.
\end{abstract}

Conclusion: The findings suggest that these hybrid-derivative lines with stripe rust resistance could potentially be used as germplasm sources for further wheat improvement.

Keywords: Genomic in situ hybridization, Stripe rust, Thinopyrum elongatum, Hybrid progeny

\section{Background}

Sichuan is the largest wheat-producing region in southwest China, both in cultivatable land area and yield. Although many wheat varieties have been cultivated over the years, Sichuan currently faces a lack of breakthrough varieties that is mirrored in reduced grain quality and resistance to pathogens. Wheat stripe rust is one of the most serious wheat diseases. Therefore, stripe rust resistance gene $\mathrm{Yr} 26$ has been widely used in wheat breeding

\footnotetext{
* Correspondence: houyang.kang@sicau.edu.cn

${ }^{1}$ Triticeae Research Institute, Sichuan Agricultural University, 211 Huimin

Road, Wenjiang, Chengdu, Sichuan 611130, China

Full list of author information is available at the end of the article
}

programs since its discovery in the early 1990s [1]. However, dependence on a single gene can be risky, as the rise of new virulent strains (such as the Yr26-virulent race V26/Gui 22) can easily lead to a significant decline in wheat production. $\operatorname{Yr} 26$ virulence may represent a major threat to wheat production in the Sichuan Basin and other regions of China [1]. The use of cultivars harboring novel resistance is an efficient and economical alternative to control wheat stripe rust [2]. The yield and quality of common wheat (Triticum aestivum L., $2 n=$ $6 x=42$, AABBDD), which accounts for $95 \%$ of domesticated wheat in globally, can be improved by modifications of its genetic background [3]. Wild relatives of 
common wheat display numerous desirable agronomic traits, including strong adaptability, resistance to biotic and abiotic stress, and high-quality of wheat, and might thus potentially enrich the genetic repertoire of domesticated wheat species [4,5]. Distant hybridization is a commonly used approach to modify the genetic background of common wheat in order to introduce the beneficial traits of wild species into the genome of domestic wheat $[6,7]$. To date, numerous related species from the tribe Triticeae, including those from genera Aegilops, Agropyron, Dasypyrum, Hordeum, Leymus, Lophopyrum, Psathyrostachys, Secale, and Thinopyrum, have been successfully crossed with wheat, and the resulting cultivars have contributed significantly to wheat production worldwide [8-13].

Thinopyrum elongatum (syn. Lophopyrum elongatum or Agropyron elongatum) is a perennial herb of the tribe Triticeae that plays a prominent role as a gene pool source for genomic improvement of common wheat through hybridization. The taxon contains various cytotypes differing in genomic composition and ploidy level: diploid $\left(2 n=2 \times=14\right.$, EE, syn. $\left.E^{\mathrm{e}} \mathrm{E}^{\mathrm{e}}\right)$, tetraploid $(2 n=4 \times$ $\left.=28, E^{e} E^{e} E^{b} E^{b}\right)$, hexaploid $\left(2 n=6 \times=42, E^{e} E^{e} E^{b} E^{b} E^{b} E^{b}\right)$, and decaploid $\left(2 n=10 \times=70, \quad E^{e} E^{e} E^{b} E^{b} E^{x} E^{x} S t S t S t S t\right)$ [14-16]. The E genome of the diploid Th. elongatum is the basal genome of the taxon [14, 15]. Th. elongatum has many agronomically desirable traits, including highquality pasture resources, high protein content, and tolerance to salt, drought, and cold [17]. Several significant global advancements in wheat-Th. elongatum hybridization have been developed since the beginning of the twentieth century [18]. As example, Li and colleagues synthesized the first common wheat-Th. elongatum hybrids in China and developed a series of new wheat cultivars, such as allogeneic octoploid Trititrigia Xiaoyan 4, 5 and $6[19,20]$. Subsequently, the Chinese Spring-Th. elongatum addition and substitution lines were successfully bred by Dvorak et al. [21]. Recent studies have uncovered that chromosomes $1 \mathrm{E}$ and $7 \mathrm{E}$ confer wheat resistance to Fusarium head blight (FHB), and the source of resistance was pinpointed to a gene located on chromosome 7ES [22, 23]. Most recently, multiple disease resistance genes were identified in the genus Thinopyrum and they were transferred successfully to common wheat, including genes conferring resistance to stem rust (Sr24, Sr25, Sr26, Sr43, and Sr44), leaf rust ( $L r 19, L r 24, L r 29$, and $L r 38)$, stripe rust ( $Y r 50)$ and powdery mildew (Pm40 and Pm43) [24-27].

The hexaploid Trititrigia $8801(2 n=6 \times=42$, AABBEE $)$ is a genetically stable partial amphidiploid line induced by hybridization of Triticum durum with tetraploid Th. elongatum Ae41 $\left(2 n=4 \times=28, \mathrm{E}_{1} \mathrm{E}_{1} \mathrm{E}_{2} \mathrm{E}_{2}\right)$ [28]. It harbors genes of Th. elongatum Ae41 that protect against many adverse conditions including stripe rust, powdery mildew, FHB, smut, cold, drought, and salinity [29]. However, owing to its extended growth period and the presence of many alien chromosomes, it is impractical for direct use in the wheat breeding industry. Instead, it is more commonly used as a genetic bridge to transfer alien genes and to create addition, substitution, and translocation lines that can be readily employed in wheat breeding [29]. Moreover, the genetic stability and compensatory effect of translocation lines are superior to those of the addition and substitution lines, thus a translocation line is of potentially greater value in breeding and is more highly regarded by breeders [30].

The objective of the present study was to identify the hybrid progenies derived from crosses between Trititrigia 8801 and prevalent T. aestivum cultivars grown in the Sichuan region. Using genomic in situ hybridization (GISH) and stripe rust resistance evaluation, we intend to perform a screen to identify genetically stable wheatTh. elongatum progeny lines exhibiting enhanced resistance to stripe rust (Fig. 1). We identified several lines that have the potential to serve as genetic resources for breeding to improve the wheat yield and quality in the Sichuan Basin.

\section{Methods}

\section{Plant material}

The hexaploid Trititrigia $8801(2 n=6 x=42$, AABBEE), which exhibits strong resistance to $\mathrm{FHB}$, stripe rust, and powdery mildew, and wide adaptability including cold, drought, and salt tolerance, was kindly provided by Dr. George Fedak (Eastern Cereal and Oilseed Research Center, Ottawa, Canada). Here we used T. aestivum cultivars $(2 n=6 \times=42$, AABBDD) Shumai482 (SM482) and Chuannong16 (CN16) as the parental genotypes susceptible to stripe rust. Fifty progeny lines were derived by hybridization of SM482 and CN16 with Trititrigia 8801 (Table 1). The wheat line SY95-71 was used as a susceptible control in stripe rust resistance tests. For GISH analysis, the Sichuan wheat cultivar J-11 $(2 n=6 \times=42$, AABBDD) was used to generate blocking DNA, and the total genomic DNA of tetraploid Th. elongatum accession PI531750 $(2 n=4 \times=28$, EEEE) was used to generate probes for labeling.

\section{Genomic in situ hybridization}

Total genomic DNA of PI531750 and J-11 was isolated using the cetyltrimethylammonium bromide (CTAB) method [31]. PI531750 DNA was labeled with digoxigenin-11-dUTP (or biotin-11-dUTP) by nick translation (Roche, Mannheim, Germany) and used as a probe. Unlabeled J-11 DNA was fragmented to 300-500 base pairs by autoclaving at $100 \mathrm{kPa}, 115{ }^{\circ} \mathrm{C}$ for $10 \mathrm{~min}$ and subsequently was used for a competitor to block $\mathrm{A}$, $\mathrm{B}$, and D-genome sequences from hybridization. 


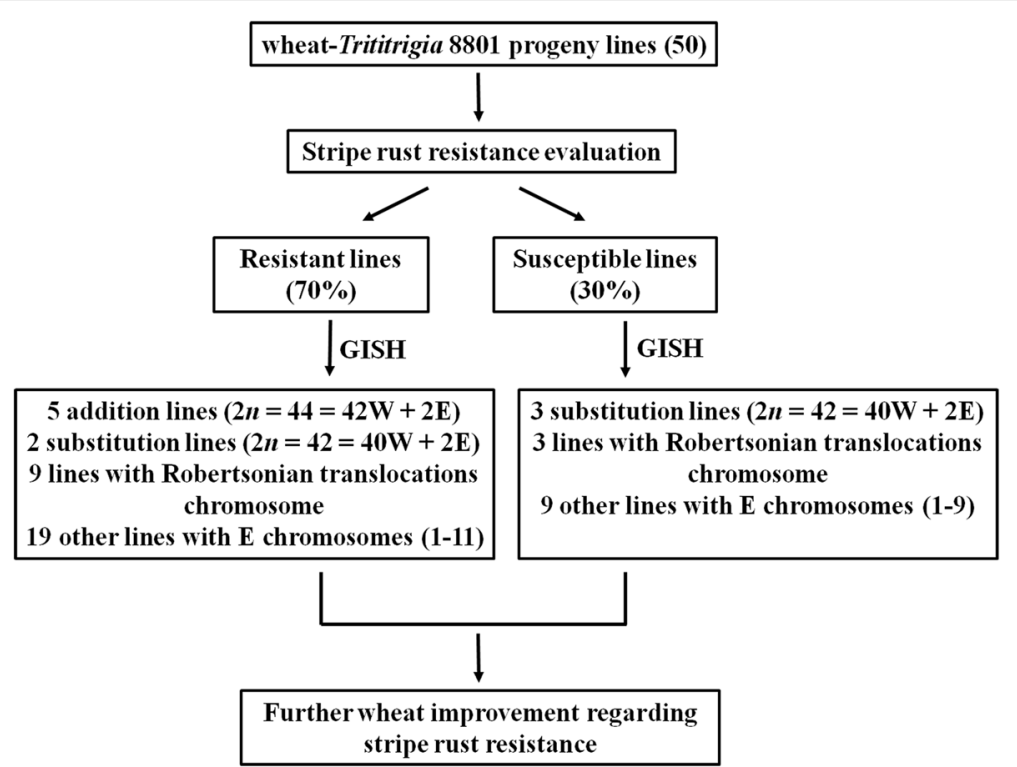

Fig. 1 Cytogenetics and stripe rust resistance of wheat-Thinopyrum elongatum hybrid derivatives in this study

Seedling root tips were collected and treated with nitrous oxide for $4 \mathrm{~h}, 90 \%$ acetic acid for $10 \mathrm{~min}$, and digestion by pectinase and cellulase, using the procedure of Komuro et al. [32]. Slides for GISH were prepared as previously described by Han et al. [33], with slight modifications. The hybridization mixture was composed of $37.5 \%$ deionized formamide, $15 \%$ dextran sulfate, $7.5 \%$ $20 \times$ SSC, and $75 \mu \mathrm{g}$ salmon sperm DNA (initial concentration $10 \mu \mathrm{g} / \mu \mathrm{L}$ ), as well as $50 \mathrm{ng}$ probe DNA (initial concentration $100 \mathrm{ng} / \mu \mathrm{L}$ ) and $7.5 \mu \mathrm{g}$ blocking agent DNA (initial concentration $1250 \mathrm{ng} / \mu \mathrm{L}$ ), and the proportion was 1:150 of probe and competitive DNA. A total volume $20 \mu \mathrm{L}$ of solution was loaded per slide and were denatured together by heating at $80{ }^{\circ} \mathrm{C}$ for $5 \mathrm{~min}$, incubated for $8-12 \mathrm{~h}$ at $37{ }^{\circ} \mathrm{C}$. Digoxigenin was detected using anti-digoxigenin-rhodamine Fab fragments (Roche, Mannheim, Germany) and biotin was detected with streptavidin-FITC (Roche). Chromosomes were counterstained with 4-6-diamino-2-phenylindole (DAPI) or propidium iodide (PI) solution (Vector Laboratories, Inc., Burlingame, CA, USA). Chromosome images were taken with an Olympus BX-51 microscope equipped with a DP-70 CCD camera. All images were processed using Adobe Photoshop CS 5.0.

\section{Stripe rust resistance screening}

Parental species 8801, SM482 and CN16, derived offspring lines, and the control line SY95-71 were each evaluated for seedling and adult plant responses to stripe rust. Stripe rust tests were performed at the Wenjiang experimental station of Sichuan Agricultural University, Chengdu, Sichuan, China. For each line, plants were grown annually in $2 \mathrm{~m}$ rows, with inter-plant spacing of
$10 \mathrm{~cm}$ and inter-row spacing of $30 \mathrm{~cm}$. The stripe rust susceptible spreader line SY95-71 was planted on both sides of each experimental row. The SY95-71 rows were inoculated at the two-leaf stage with a mixture of fresh urediniospores and talc (1:20 ratio). The Pst races (CYR32, CYR-33, V26/Gui22-9, V26/Gui22-14, Su4, and Su5) were supplied by the Research Institute of Plant Protection, Gansu Academy of Agricultural Sciences, Gansu, China. Stripe rust infection types (IT) were recorded on a scale of $0-4$. The plants scored with IT 2 or lower were considered as resistant, whereas the plants with IT 3 or 4 were considered as susceptible. Infection was scored three times, when uniform rust stripe severity was observed on SY95-71 during the booting, flowering, and milky stages [34].

\section{Results}

\section{GISH analysis of hybrid progenies}

Chromosome numbers for 50 randomly selected progeny are presented in Table 1 . The mean chromosome number of all hybrid progenies was $2 n=42.72$, with a range of $40-47$. Most lines (94.0\%) were $2 n=41-45$. Of these, progenies with 42 chromosomes were predominant $(40 \%)$, whereas the remainder of the progeny displayed various degrees of aneuploidy $(2 n=44,43,45,41$, $40,47)$ where the order reflects the decreasing proportion of incidence $(16.0 \%, 14.0 \%, 12.0 \%, 12.0 \%, 4.0 \%$ and $2.0 \%)$. Among these lines with 42 chromosomes, K13415-3, K14-480-2 and K15-1016-12 derived from the crosses of Trititrigia 8801 with SM482 showed the greatest degree of cytological stability. By contrast, some lines exhibited loss of chromosomes, such as K13-415-1 and K15-1007-5 (from 43 to 42). Collectively, these 
Table 1 Chromosome number and stripe rust response of hybrid progenies

\begin{tabular}{|c|c|c|c|c|c|c|c|c|}
\hline \multirow[b]{2}{*}{ Lines } & \multirow[b]{2}{*}{ Materials } & \multirow[b]{2}{*}{ Generation } & \multicolumn{4}{|c|}{ Chromosome Numbers } & \multirow{2}{*}{$\begin{array}{l}\text { Infection } \\
\text { type }\end{array}$} & \multirow{2}{*}{$\begin{array}{l}\text { Resistance/ } \\
\text { susceptibility }\end{array}$} \\
\hline & & & $2 n$ & $E$ & W & W/E & & \\
\hline & SY95-71 & & 42 & & 42 & & 4 & S \\
\hline & SM482 & & 42 & & 42 & & 4 & S \\
\hline & CN16 & & 42 & & 42 & & 4 & S \\
\hline & 8801 & & 42 & 14 & 28 & & 0 & $\mathrm{R}$ \\
\hline K13-415-1 & $8801 \times$ SM482 & $\mathrm{F}_{2}$ & 43 & 5 & 37 & 1 & 4 & $S$ \\
\hline K13-415-2 & $8801 \times$ SM482 & $\mathrm{F}_{2}$ & 42 & 6 & 35 & 1 & 4 & S \\
\hline K13-415-3 & $8801 \times$ SM 482 & $\mathrm{~F}_{2}$ & 42 & 9 & 33 & & 4 & S \\
\hline K13-415-4 & $8801 \times$ SM482 & $\mathrm{F}_{2}$ & 42 & 5 & 37 & & 4 & S \\
\hline K13-422-1 & $8801 \times$ CN16 & $\mathrm{F}_{2}$ & 43 & 7 & 36 & & 0 & $\mathrm{R}$ \\
\hline K13-437-3 & $8801 /$ SM482// SM482 & $\mathrm{BC}_{1} \mathrm{~F}_{1}$ & 40 & 3 & 37 & & 3 & $S$ \\
\hline K13-437-4 & $8801 /$ SM482// SM482 & $\mathrm{BC}_{1} \mathrm{~F}_{1}$ & 41 & 7 & 33 & 1 & 0 & $\mathrm{R}$ \\
\hline K13-438-4 & $8801 /$ SM482//11 N21 & $F_{1}$ & 40 & 3 & 37 & & 0 & $\mathrm{R}$ \\
\hline K13-439-1 & 8801/ SM482// SM969 & $\mathrm{F}_{1}$ & 45 & 3 & 42 & & 4 & $S$ \\
\hline K13-439-4 & 8801/ SM482// SM969 & $\mathrm{F}_{1}$ & 42 & 4 & 38 & & 4 & S \\
\hline K13-440-2 & 8801/ SM482//N08-51 & $\mathrm{F}_{1}$ & 42 & 3 & 39 & & 0 & $\mathrm{R}$ \\
\hline K14-478-6 & $8801 \times$ SM482 & $\mathrm{F}_{3}$ & 42 & 5 & 36 & 1 & 0 & $\mathrm{R}$ \\
\hline K14-479-4 & $8801 \times$ SM482 & $\mathrm{F}_{3}$ & 44 & 1 & 42 & 1 & 4 & S \\
\hline K14-480-2 & $8801 \times$ SM482 & $\mathrm{F}_{3}$ & 42 & 2 & 40 & & 4 & S \\
\hline K14-485-1 & $8801 \times \mathrm{CN} 16$ & $\mathrm{~F}_{2}$ & 43 & 8 & 35 & & 0 & $\mathrm{R}$ \\
\hline K14-490-4 & $8801 \times C N 16$ & $\mathrm{~F}_{2}$ & 42 & 11 & 31 & & 0 & $\mathrm{R}$ \\
\hline K14-499-3 & 8801/ SM482// SM482 & $\mathrm{BC}_{1} \mathrm{~F}_{2}$ & 44 & 3 & 41 & & 3 & S \\
\hline K14-500-4 & $8801 /$ SM482// SM482 & $\mathrm{BC}_{1} \mathrm{~F}_{2}$ & 42 & 2 & 39 & 1 & 0 & $\mathrm{R}$ \\
\hline K14-501-3 & 8801 / SM482 // 11 N21 & $\mathrm{F}_{2}$ & 44 & 2 & 42 & & 2 & $\mathrm{R}$ \\
\hline K14-501-4 & 8801 / SM482 // 11 N21 & $F_{2}$ & 42 & 2 & 40 & & 1 & $\mathrm{R}$ \\
\hline K14-501-5 & 8801 / SM482 // 11 N21 & $\mathrm{F}_{2}$ & 41 & 1 & 40 & & 1 & $\mathrm{R}$ \\
\hline K14-502-1 & 8801 / SM482 // 11 N21 & $\mathrm{F}_{2}$ & 43 & 3 & 40 & & 0 & $\mathrm{R}$ \\
\hline K14-502-3 & 8801 / SM482 // 11 N21 & $\mathrm{F}_{2}$ & 43 & 1 & 41 & 1 & 0 & $\mathrm{R}$ \\
\hline K14-502-5 & 8801 / SM482 // 11 N21 & $\mathrm{F}_{2}$ & 47 & 5 & 42 & & 0 & $\mathrm{R}$ \\
\hline K14-509-1 & 8801 / SM482 // SM969 & $\mathrm{F}_{2}$ & 42 & 1 & 41 & & 3 & $\mathrm{R}$ \\
\hline K14-511-9 & 8801 / SM482 // SM51 & $\mathrm{F}_{2}$ & 42 & 1 & 41 & & 4 & $S$ \\
\hline K14-516-2 & 8801 / SM482 // SM51 & $\mathrm{F}_{2}$ & 44 & 5 & 39 & & 0 & $\mathrm{R}$ \\
\hline K14-516-4 & 8801 / SM482 // SM51 & $\mathrm{F}_{2}$ & 45 & 6 & 39 & & 0 & $\mathrm{R}$ \\
\hline K14-528-1 & $8801 /$ SM482 F //SM482 & $F_{1}$ & 45 & 4 & 41 & & 4 & S \\
\hline K14-528-4 & 8801 / SM482 F //SM482 & $\mathrm{F}_{1}$ & 42 & 2 & 40 & & 4 & $S$ \\
\hline K14-562-1 & 8801 / CN16 // CN16 & $\mathrm{BC}_{1} \mathrm{~F}_{1}$ & 42 & 3 & 39 & & 2 & $\mathrm{R}$ \\
\hline $\mathrm{K} 14-637-2$ & 8801 / SM482 // SM482 /// SM482 & $\mathrm{BC}_{2} \mathrm{~F}_{1}$ & 43 & 1 & 42 & & 0 & $\mathrm{R}$ \\
\hline K15-1007-1 & $8801 \times$ SM482 & $\mathrm{F}_{4}$ & 41 & 4 & 36 & 1 & 1 & $\mathrm{R}$ \\
\hline K15-1007-3 & $8801 \times$ SM482 & $\mathrm{F}_{4}$ & 42 & 5 & 37 & & 1 & $\mathrm{R}$ \\
\hline K15-1007-5 & $8801 \times$ SM482 & $\mathrm{F}_{4}$ & 42 & 4 & 37 & 1 & 1 & $\mathrm{R}$ \\
\hline K15-1016-12 & $8801 \times \mathrm{SM} 482$ & $\mathrm{~F}_{4}$ & 42 & 2 & 40 & & 3 & S \\
\hline K15-1033-8 & 8801/ SM482 // SM482 & $\mathrm{BC}_{1} \mathrm{~F}_{3}$ & 43 & 3 & 39 & 1 & 0 & $\mathrm{R}$ \\
\hline K15-1035-11 & $8801 /$ SM482 // 11 N21 & $\mathrm{F}_{3}$ & 44 & 2 & 42 & & 2 & $\mathrm{R}$ \\
\hline K15-1035-12 & $8801 /$ SM482 // 11 N21 & $\mathrm{F}_{3}$ & 42 & 2 & 40 & & 2 & $\mathrm{R}$ \\
\hline
\end{tabular}


Table 1 Chromosome number and stripe rust response of hybrid progenies (Continued)

\begin{tabular}{|c|c|c|c|c|c|c|c|c|}
\hline \multirow[b]{2}{*}{ Lines } & \multirow[b]{2}{*}{ Materials } & \multirow[b]{2}{*}{ Generation } & \multicolumn{4}{|c|}{ Chromosome Numbers } & \multirow{2}{*}{$\begin{array}{l}\text { Infection } \\
\text { type }\end{array}$} & \multirow{2}{*}{$\begin{array}{l}\text { Resistance/ } \\
\text { susceptibility }\end{array}$} \\
\hline & & & $2 n$ & $E$ & W & W/E & & \\
\hline K15-1035-13 & $8801 /$ SM482 // 11 N21 & $\mathrm{F}_{3}$ & 44 & 2 & 42 & & 2 & $\mathrm{R}$ \\
\hline K15-1036-13 & $8801 /$ SM482 // 11 N21 & $\mathrm{F}_{3}$ & 45 & 3 & 42 & & 1 & $\mathrm{R}$ \\
\hline K15-1049-1 & 8801 / SM482 // SM51 & $\mathrm{F}_{3}$ & 45 & 6 & 39 & & 1 & $\mathrm{R}$ \\
\hline K15-1049-4 & 8801 / SM482 // SM51 & $\mathrm{F}_{3}$ & 45 & 2 & 42 & 1 & 2 & $\mathrm{R}$ \\
\hline K15-1048-10 & 8801 / SM482 // SM51 & $F_{3}$ & 41 & 4 & 37 & & 0 & $\mathrm{R}$ \\
\hline K15-1058-5 & $8801 / \mathrm{CN} 16 / / \mathrm{CM} 104$ & $\mathrm{~F}_{2}$ & 41 & 1 & 40 & & 3 & S \\
\hline K15-1020-4 & $8801 \times$ CN16 & $\mathrm{F}_{3}$ & 42 & 10 & 31 & 1 & 0 & $\mathrm{R}$ \\
\hline K15-1053-3 & 8801 /CN16 // aobaimai3 & $\mathrm{F}_{2}$ & 41 & 1 & 40 & & 1 & $\mathrm{R}$ \\
\hline K15-1083-1 & 8801/ SM482 // SM482 F /// SM482 & $F_{1}$ & 44 & 2 & 42 & & 1 & R \\
\hline K15-1035-4 & 8801/ SM482 // 11 N21 & $\mathrm{F}_{3}$ & 44 & 2 & 42 & & 2 & $\mathrm{R}$ \\
\hline K15-1005-3 & $8801 \times$ SM482 & $\mathrm{F}_{4}$ & 42 & 6 & 36 & & 1 & $\mathrm{R}$ \\
\hline
\end{tabular}

Abbreviations: E E-genome chromosomes of Th. elongatum, W A, B, and D-genome chromosomes of wheat, W/E translocation chromosome of wheat-Th. elongatum. The wheat line SY95-71 was used as a susceptible control. Infection type was based on a scale of 0-4, where $0=$ resistant, and 1-4 indicate increasing sporulation and decreasing necrosis or chlorosis, considered highly resistant, resistant, susceptible, and highly susceptible, respectively

observations indicated that the chromosome number of 8801-derived hybrid progeny tended to conform with the chromosome number of common wheat $(2 n=42)$.

To identify the alien chromosomes derived from Trititrigia 8801 in the 50 progeny lines, we performed GISH using genomic DNA of tetraploid Th. elongatum accession PI531750 as a probe. The number of Th. elongatum chromosomes in the progeny lines ranged from 1 to 11 (Table 2). Figure 2 provides representative examples of chromosome substitution (Fig. 2a-d), addition (Fig. 2e, f), addition-substitution (Fig. 2g-i), and translocation (Fig. $2 \mathrm{j}-\mathrm{l}$ ) in the progeny. Most of the resulting daughter plants (42\%) represent substitution lines, in which from one up to 11 chromosomes of common wheat were replaced by E-specific chromosomes (Fig. 2a-d). Among the lines possessing 42 chromosomes, five exhibited substitution with two E chromosomes (Fig. 2b). Chromosome addition $(2 n>42)$ was detected in nine lines, with up to five $\mathrm{E}$ chromosomes being added (Fig. 2e, f). Five lines possessed 44 chromosomes, with two additional $\mathrm{E}$ chromosomes (Fig. 2e). We also identified eight

Table 2 Chromosome constitutions of hybrid progenies

\begin{tabular}{lll}
\hline $\begin{array}{l}\text { Chromosome } \\
\text { number }\end{array}$ & $\begin{array}{l}\text { Number } \\
\text { of lines }\end{array}$ & $\begin{array}{l}\text { Number of E chromosomes } \\
\text { (number of lines) }\end{array}$ \\
\hline 40 & 2 & $3(2)$ \\
41 & 6 & $1(3), 4(1), 4.5(1), 7.5(1)$ \\
42 & 20 & $\begin{array}{l}1(2), 2(5), 2.5(1), 3(2), 4(1), 4.5(1), 5(2), \\
5.5(1), 6(1), 6.5(1), 9(1), 10.5(1), 11(1)\end{array}$ \\
43 & 7 & $1(1), 1.5(1), 3(1), 3.5(1), 5.5(1), 7(1), 8(1)$ \\
44 & 8 & $1.5(1), 2(5), 3(1), 5(1)$ \\
45 & 6 & $2.5(1), 3(2), 4(1), 6(2)$ \\
47 & 1 & $5(1)$ \\
\hline
\end{tabular}

addition-substitution lines (Fig. 2g-i). In line K13-422-1 $(2 n=43=36 \mathrm{~W}+7 \mathrm{E})$, for example, six common wheat chromosomes were replaced and one additional $\mathrm{E}$ chromosome was inserted. Most importantly, a single product of intergenomic (wheat-Th. elongatum) Robertsonian $(\mathrm{Rb})$ translocation was observed uniformly in 12 progeny lines (Fig. $2 \mathrm{j}-\mathrm{l}$ ). In addition, during the process of selfing (e.g. K13-415-2) or backcrossing (e.g. K13422-1), majority of the alien chromisomes have been lost and, in some plants, they were completely lacking. The above-mentioned examples indicated that lines with $2 n$ $=42$ or $2 n=44$ may be cytologically stable, and those with a $\mathrm{Rb}$ translocation may loose the chromosomes in the process of transmission to the next generation, or form a new pair of stable translocation chromosomes by recombination.

\section{Stripe rust resistance evaluation}

Each of the 50 derivative lines, the parental lines (8801, SM482 and CN16), and a stripe rust-sensitive control line (SY95-71) was evaluated for stripe rust resistance using a mixture of Pst races (see Materials and Methods). Representative examples of stripe rust resistance are provided in Fig. 3. At the seedling and adult plant stages, the 8801 parental line was highly resistant to stripe rust $(\mathrm{IT}=0)$. By contrast, SM482, CN16, and SY95-71 showed IT scores of 4, indicating susceptibility to stripe rust (Table 1). Of the 50 derivative lines, 35 (70.0\%) exhibited resistance to stripe rust, whereas the remaining 15 (30\%) were susceptible.

\section{Discussion}

Distant hybridization is a promising method to transfer agronomically valuable genes from wild relatives to 

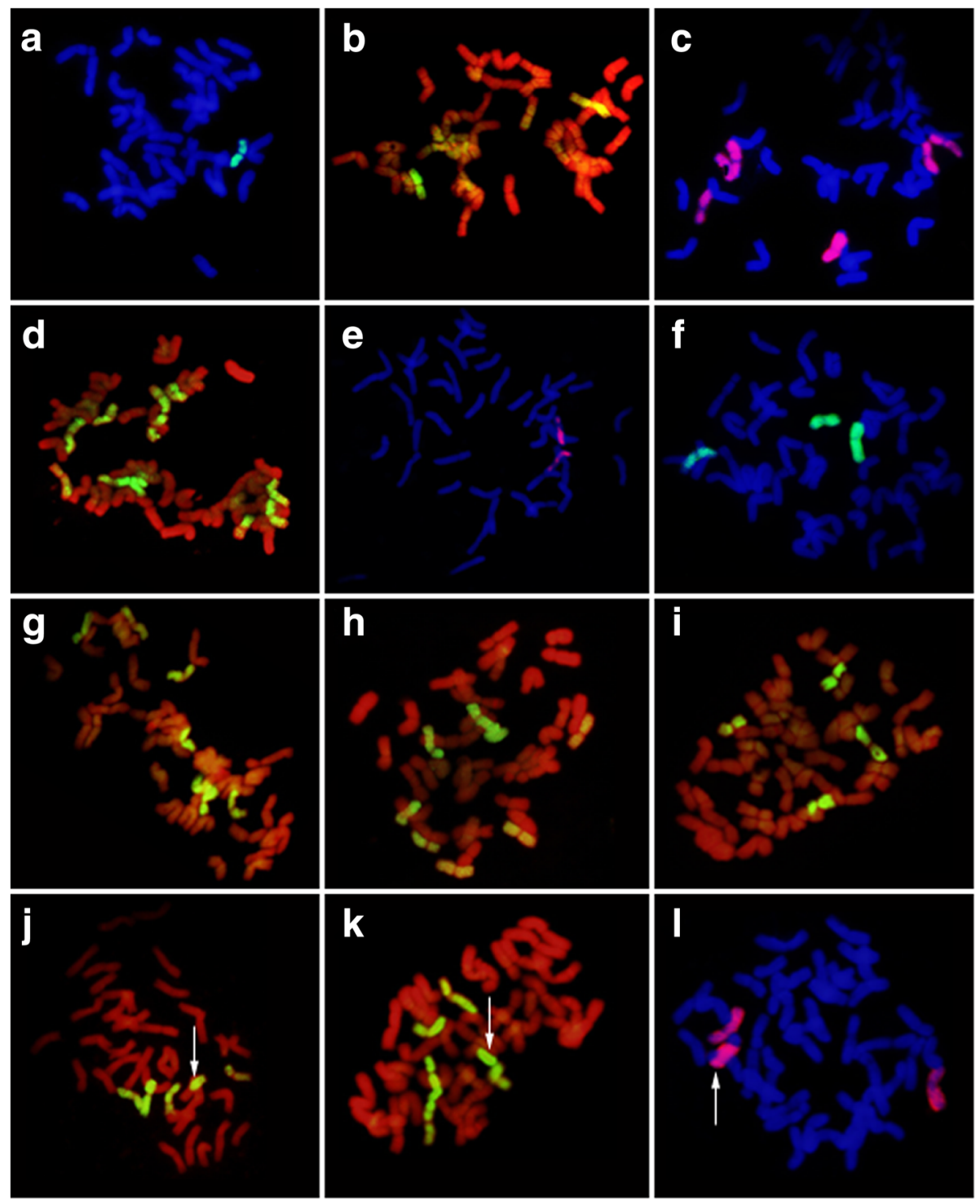

Fig. 2 GISH analysis of hybrid progenies at mitotic metaphase. Thinopyrum elongatum genomic DNA was used as a probe for in situ hybridization. Chromosomes in red and blue are derived from wheat (W); chromosomes in yellow-green, green, and pink are derived from Th. elongatum (E). Arrows indicate Robertsonian translocations. a K15-1058-5, $2 n=41=1 \mathrm{E}+40 \mathrm{~W}$; (b) $\mathrm{K} 14-480-2,2 n=42=2 \mathrm{E}+40 \mathrm{~W}$; (c) $\mathrm{K} 15-1005-3$, $2 n=42=6 \mathrm{E}+36 \mathrm{~W} ;$ (d) K14-490-4, $2 n=42=11 \mathrm{E}+31 \mathrm{~W}$; (e) K15-1083-1, 2n=44=2E + 42 W; (f) K15-1036-13, 2n=45=3E+42 W; (g) K13-422$1,2 n=43=7 \mathrm{E}+36 \mathrm{~W}$; (h) K14-485-1, 2n=43=8E+35 W; (i) K14-528-1, 2n=45=4E+41 W; (j) K15-1007-1, 2n=41=4E+ 1 W/E + 36 W; (k) $\mathrm{K} 14-478-6,2 n=42=5 \mathrm{E}+1 \mathrm{~W} / \mathrm{E}+36 \mathrm{~W}$; (I) K15-1049-4, 2n=45=2E+ $1 \mathrm{~W} / \mathrm{E}+42 \mathrm{~W}$

common wheat. Creating intermediate lines carrying alien chromosomes provides a basis for using germplasm resources of wheat relatives to improve domesticated wheat $[35,36]$. Th. elongatum harbors many beneficial genes that protect against adverse conditions such as disease, cold, drought, and salinity, and thus represents a promising gene donor to improve tolerance to biotic or abiotic stresses in common wheat [37-39]. In the current study, we produced hybrid progenies by crossing a Triticum durum-Th. elongatum partial amphidiploid (Trititrigia 8801, $2 n=6 \times=42$, AABBEE) with prevalent wheat cultivars grown in the Sichuan area. A previous study demonstrated that the chromosome number of derivative progeny is gradually reaching back the natural chromosome number of $T$. aestivum $(2 \mathrm{n}=42)$ with each subsequent generation, and a similar phenomenon has been observed in both inbred and backcross lines [40]. In the present study, we provided another evidence that the number of chromosomes in hybrid progenies approaches 42 ( $T$. aestivum L., $2 n=42$ ). It is often observed that chromosomes of different parental subgenomes segregate unequally to daughter cells in 


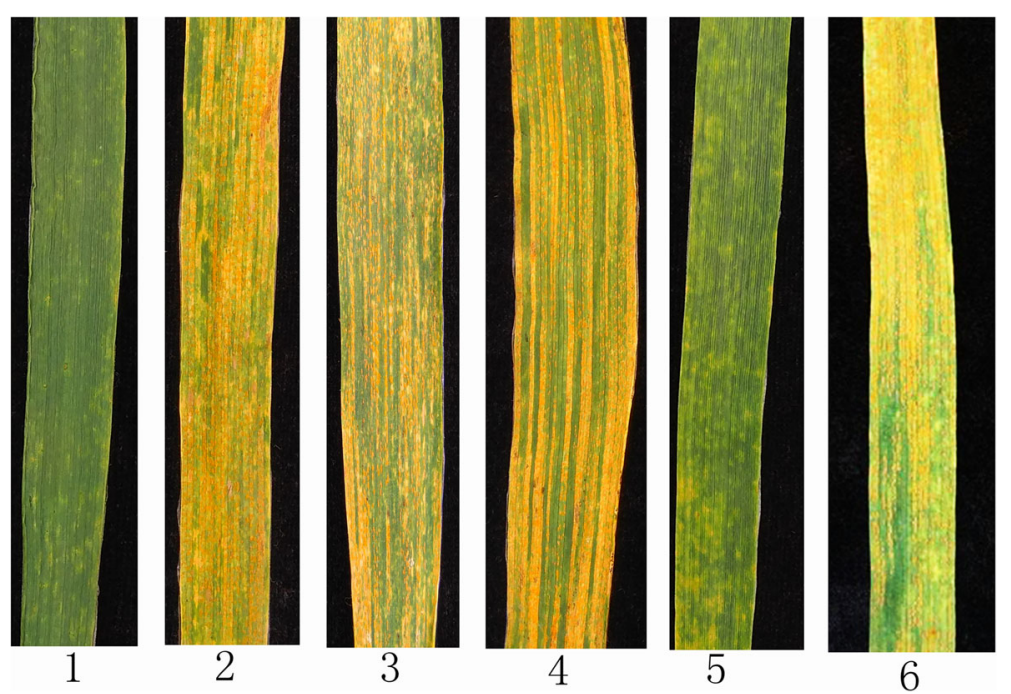

Fig. 3 Representative examples of stripe rust resistance in parental lines, hybrid progeny, and controls. (1) Trititrigia 8801; (2) T. aestivum Shumai482; (3) T. aestivum Chuannong16; (4) T. aestivum SY95-71; (5) resistant derivative line K15-1007-1; (6) susceptible derivative line K15-1016-12

progeny derived from distant hybridization. Such observation may result from the chromosome elimination during mitosis $[41,42]$. Also in our study, we observed unequal chromosome divisions. For example, K13-4151, K13-415-2, K13-415-3, and K13-415-4 are derived from the same individual parental lines but differed in chromosome number. Likewise, K14-485-1 and K14490-4 were derived from the same parental lines (Trititrigia 8801 and $\mathrm{CN} 16$ ) and also differed in chromosome number.

Identification of alien chromosomes against the wheat chromosome background is an essential step in utilizing alien genetic resources. The $\mathrm{Rb}$ translocations typically result from erroneous repair of double strand breaks (by NHEJ pathway), where the p-arms and possibly also one centromere from the original monoarmed chromosome are lost [43]. In the wheat meiosis the process, sister centromeres often lose their coordination in metaphase I and lead to stable bipolar attachment and frequent separation of sister chromatids or to misdivision in the progression of anaphase I, and misdivision may occur across the centromere region or across thepericentric chromatin and subsequent fusion of broken centromeres [44]. In the present study, GISH revealed that all translocated chromosomes had undergone $\mathrm{Rb}$ translocation. The line K13-415-1 had a Rb translocation chromosome transmitted to the following generation by single-seed descent, which indicated that this translocation chromosome may remain stable in future generations. Furthermore, some generations derived by single-seed descent from the same parental lines, such as line K13-438-4, showed an elevated number of chromosomes produced by $\mathrm{Rb}$ translocations, which indicated that continuous selfing favors the inheritance of alien chromosomes in future generations and contributes to the appearance of new alien types. A similar phenomenon was observed in a previous study by Guan [45]. The formation of a new translocation is probably due to multiple chromosomes breakages in late meiosis at the same time fracture, and chromosomal fragments are misjoined to form aberrant novel chromosome [46]. In addition, the present GISH analysis showed that during the process of selfing or backcrossing, alien chromosomes are predominantly lost or (in some individuals) completely lost. Our findings are in agreement with previous study of Wu et al. [47] in the sense that the plants from the earlier generations tend to sustain/retain more alien chromosomes in comparison to those of later generations. With increase in number of selfing or backcrossing generations, alien chromosome differentiation occurs. In the present study, we identified five relatively stable addition lines $(2 n=44$ $=42 \mathrm{~W}+2 \mathrm{E})$ and five substitution lines $(2 n=42=40 \mathrm{~W}$ $+2 \mathrm{E})$. Furthermore, a previous study indicated that partial homology exists between wheat and Th. elongatum [48], and Cai et al. [49] identified genes that promote partial homologous chromosome pairing in Th. elongatum. In addition, in wheat, $P h 1$ is a major chromosome pairing locus facilitating correct pairing of homologous, and in wheat hybrids $P h 1$ prevents pairing between related chromosomes $[35,50,51]$. This may be another important reason for the chromosome pairing diversity of Th. elongatum and different wheat-derived hybrids observed in the present study.

The Sichuan Basin is one of the most important regions for wheat production in China, but it has suffered a serious stripe rust epidemy in recent years. In this 
study, a series of stripe rust-resistant strains was obtained through distant hybridization with strains carrying E-genome chromosomes. Further work is needed to identify the genomic composition of these lines by fluorescence in situ hybridization (FISH) and to evaluate their agronomic performance. Nevertheless, these lines provide novel and valuable bridge resources for improvement of stripe rust resistance in wheat.

\section{Conclusion}

The use of amphiploid provides a facile method to transfer alien genes to common wheat compared with the direct use of wild species [52]. In this study, we selected and identified substitution, addition, and translocation lines that exhibited high resistance to stripe rust. Although the experimental lines are still in early generation, these lines have the potential to serve as primary material for wheat genetic improvements. Further work is needed to identify the genomic composition of these lines by FISH and to evaluate their agronomic performance. In conclusion, genes with desirable traits were transferred to wheat, thereby extending the genetic source of wheat breeding, enriching genetic diversity and improving the yield and quality of wheat.

\section{Acknowledgments}

We thank Dr. George Fedak, Eastern Cereal and Oilseed Research Center, Ottawa, Canada, for kindly supplying the Trititrigia 8801 material used in this study. We thank Robert McKenzie, PhD, from Liwen Bianji, Edanz Group China (https://www.liwenbianji.cn), for editing the English text of a draft of this manuscript. We thank the anonymous reviewers of the manuscript for their useful comments.

\section{Funding}

This work was funded by the National Key Research and Development Program of China (2016YFD0102000, 2017YFD0100905), the National Natural Science Foundation of China (No. 31501311, 31771781), and the Science and Technology Bureau of Sichuan Province (No. 2016HH0048).

\section{Availability of data and materials}

All data generated or analysed during this study are included in this published article.

\section{Authors' contributions \\ HYK conceived and designed the research. DYL, DL, THL, and YLW conducted the experiments. YW, JZ, LLX, XF, and LNS participated in the preparation of the reagents and materials. $\mathrm{HQZ}, \mathrm{YHZ}$ and $\mathrm{HYK}$ analyzed the data. DYL and DL wrote the manuscript. All the authors read and approved the manuscript.}

\section{Ethics approval and consent to participate}

Not applicable.

\section{Consent for publication}

Not applicable.

\section{Competing interests}

The authors declare that they have no competing interests.

\section{Publisher's Note}

Springer Nature remains neutral with regard to jurisdictional claims in published maps and institutional affiliations.

\section{Author details}

${ }^{1}$ Triticeae Research Institute, Sichuan Agricultural University, 211 Huimin Road, Wenjiang, Chengdu, Sichuan 611130, China. ${ }^{2}$ College of Resources, Sichuan Agricultural University, 211 Huimin Road, Wenjiang, Chengdu, Sichuan 611130, China.

Received: 11 November 2017 Accepted: 31 January 2018

Published online: 05 February 2018

\section{References}

1. Han DJ, Wang QL, Chen XM, Zeng QD, Wu JH, Xue WB, et al. Emerging Yr26 -virulent races of Puccinia striiformis $f$. tritici are threatening wheat production in the Sichuan Basin, China. Plant Dis. 2015;99(6):754-60.

2. Ren Y, Li S, Xia X, Zhou Q, He Y, Wei Y, et al. Molecular mapping of a recessive stripe rust resistance gene YrMY37 in Chinese wheat cultivar Mianmai 37. Mol Breeding. 2015;35(3):97.

3. Dubcovsky J, Dvorak J. Genome plasticity a key factor in the success of polyploid wheat under domestication. Science. 2007;316:1862-6.

4. Dong YS, Zhou RH. Xu SJ, Cauderon Y, Wang RC. Desirable characteristics in perennial Triticeae collected in China for wheat improvement. Hereditas. 1992;116:175-8.

5. Mujeeb-Kazi A, Kazi AG, Dundas I, Rasheed A, Ogbonnaya F, Kishii M, et al. Chapter four-genetic diversity for wheat improvement as a conduit to food security. In: Advances in agronomy. Edited by Dr. Sparks. Vol. 122. Burlington: academic press; 2013. p. 179-257.

6. Qi LL, Friebe B, Zhang P, Gill BS. Homoeologous recombination, chromosome engineering and crop improvement. Chromosom Res. 2007; 15(1):3-19.

7. Qi W, Tang Y, Zhu W, Li D, Diao C, Xu L, et al. Molecular cytogenetic characterization of a new wheat-rye $1 B L \cdot 1 R S$ translocation line expressing superior stripe rust resistance and enhanced grain yield. Planta. 2016;244(2): 405-16.

8. Cabrera A, Martin A. A trigeneric hybrid between Hordeum, Aegilops, and Secale. Genome. 1992;35(4):647-9.

9. Li LH, Dong YS. A self-fertile trigeneric hybrid, Triticum aestivum $\times$ Agropyron michnoi $\times$ Secale cereale. Theor Appl Genet. 1993;87(3):361-8.

10. Sun $\mathrm{GL}$, Yen $\mathrm{C}$, Yang $\mathrm{J}, \mathrm{Wu} \mathrm{BH}$. Production and cytogenetics of intergeneric hybrids between Triticum durum-Dasypyrum villosum amphidiploid and Psathyrostachys huashanica. Euphytica. 1995;81(1):7-11.

11. Mujeeb-Kazi A. Apomixis in Trigeneric hybrids of Triticum aestivum/Leymus racemosus//Thinopyrum elongatum. Cytologia. 1996;61(1):15-8.

12. Kang HY, Wang H, Huang J, Wang YJ, Li DY, Diao CD, et al. Divergent development of hexaploid triticale by a wheat - Rye -Psathyrostachys huashanica trigeneric hybrid method. PLoS One. 2016;11(5):e0155667.

13. Kang HY, Tang L, Li DY, Diao CD, Zhu W, Tang Y, et al. Cytogenetic study and stripe rust response of the derivatives from a wheat-Thinopyrum intermedium - Psathyrostachys huashanica trigeneric hybrid. Genome. 2016; 60:393-401.

14. Dewey DR. The genomic system of classification as a guide to intergeneric hybridization with the perennial triticeae. In Gene Manipulation in Plant Improvement. Edited by Gustafson, J. P. New York: Plenum Press; 1984. p. 209-210.

15. Lou H, Dong L, Zhang K, Wang DW, Zhao M, et al. High throughput mining of E-genome specific SNPs for characterizing Thinopyrum elongatum introgressions in common wheat. Mol Ecol Resour 2017; doi:https://doi.org/ 10.1111/1755-0998.12659.

16. Mao PS, Huang Y, Wang XG, Lin M, Mao PC, Zhang GF. Cytological evaluation and karyotype analysis in plant germplasms of Elytrigia Desv. Agric Sci China. 2010:9(11):1553-60.

17. Guo Q, Meng L, Mao PC, Tian XX. Salt tolerance in two tall wheatgrass species is associated with selective capacity for $\mathrm{K}^{+}$over $\mathrm{Na}^{+}$. Acta Physiol Plan. 2015;37(1):1708.

18. Dvorak J, Phylogenetic CKC. Relationships between chromosomes of wheat and chromosome. Genome. 1984;26(2):128-32.

19. Li Z, Li B, Tong Y. The contribution of distant hybridization with decaploid Agropyron elongatum to wheat improvement in China. J Genet Genomics. 2008;35(8):451-6.

20. Zhang X, Dong Y, Wang RR. Characterization of genomes and chromosomes in partial amphiploids of the hybrid Triticum aestivum $\times$ Thinopyrum ponticum by in situ hybridization, isozyme analysis, and RAPD. Genome. 1996;39(6):1062-71. 
21. Dvorak J, Sosulski FW. Effects of additions and substitutions of Agropyron elongatum chromosomes on quantitative characters in wheat. Can J Genet Cytol. 1974;16(3):627-37.

22. Jauhar PP, Peterson TS, Xu SS. Cytogenetic and molecular characterization of a durum alien disomic addition line with enhanced tolerance to fusarium head blight. Genome. 2009;52(5):467-83.

23. Fu S, Lv Z, Qi B, Guo X, Li J, Liu B, et al. Molecular cytogenetic characterization of wheat-Thinopyrum elongatum addition, substitution and translocation lines with a novel source of resistance to wheat fusarium head blight. J Genet Genomics. 2012;39(2):103-10.

24. Zhang X, Shen X, Hao Y, Cai J, Ohm HW, Kong L. A genetic map of Lophopyrum ponticum chromosome $7 \mathrm{E}$, harboring resistance genes to fusarium head blight and leaf rust. Theor Appl Genet. 2011;122(2):263-70.

25. Niu Z, DL K, Yu G, Friesen TL, Chao S, Jin Y, et al. development and characterization of wheat lines carrying stem rust resistance gene Sr43 derived from Thinopyrum ponticum. Theor Appl Genet. 2014;127(4):969-80

26. Tang X, Shi D, Xu J, Li Y, Li W, Ren Z, et al. Molecular cytogenetic characteristics of a translocation line between common wheat and Thinopyrum intermedium with resistance to powdery mildew. Euphytica. 2014; 197:201-10.

27. Li G, Wang H, Lang T, Li J, La S, Yang E, et al. New molecular markers and cytogenetic probes enable chromosome identification of wheat-Thinopyrum intermedium introgression lines for improving protein and gluten contents. Planta. 2016;244:865-76.

28. Guo X, Shi Q, Wang J, Hou Y, Wang Y, Han F. Characterization and genome changes of new amphiploids from wheat wide hybridization. J Genet Genomics. 2015;42(8):459-61.

29. Xin WL. Cytogenetic study on crosses between octoploid Trititrigia and hexaploid Trititrigia. Heilongjiang agricultural. Science. 1998;3:4-7.

30. Sears ER. Chromosome engineering in wheat. Stadler Symposia, University of Missouri, Columbia. 1972;4:23-38.

31. Allen GC, Flores-Vergara MA, Krasynanski S, Kumar S, Thompson WF. A modified protocol for rapid DNA isolation from plant tissues using cetyltrimethylammonium bromide. Nat Protoc. 2006;1(5):2320-5.

32. Komuro S, Endo R, Shikata K, Kato A. Genomic and chromosomal distribution patterns of various repeated DNA sequences in wheat revealed by a fluorescence in situ hybridization procedure. Genome. 2013;56(3):131-7.

33. Han F, Liu B, Fedak G, Liu Z. Genomic constitution and variation in five partial amphiploids of wheat-Thinopyrum intermedium as revealed by GISH, multicolor GISH and seed storage protein analysis. Theor Appl Genet. 2004; 109(5):1070-6.

34. Study LXK. On the yellow rust resistance to common wheat (T.aestivum). Plant Prot. 1988;15:33-9.

35. Liu D, Zhang H, Zhang L, Yuan Z, Hao M, Zheng Y. Distant hybridization: a tool for interspecific manipulation of chromosomes. Springer New York. 2014;9(1):e86667.

36. Kwiatek M, Belter J, Majka M, Wiśniewska H. Allocation of the S-genome chromosomes of Aegilops variabilis powdery mildew resistance in triticale (×TriticosecaleWittmack). Protoplasma. 2016;253(2):329-43.

37. Lammer D, Cai X, Arterburn M, Chatelain J, Murray T, Jones S. A single chromosome addition from Thinopyrum elongatum confers a polycarpic, perennial habit to annual wheat. J Exp Bot. 2004;55(403):1715-20.

38. Chen S, Huang Z, Dai Y, Qin S, Gao Y, Zhang L, et al. The development of 7 chromosome-specific molecular markers for Thinopyrum elongatum based on SLAF-seq technology. PLoS One. 2013;8(6):e65122.

39. Dai Y, Duan Y, Liu H, Chi D, Cao W, Xue A, et al. Molecular cytogenetic characterization of two Triticum-Secale-Thinopyrum trigeneric hybrids exhibiting superior resistance to fusarium head blight, leaf rust, and stem rust race Ug99. Front Plant Sci. 2017;8:797.

40. Wang MX, Zhang CZ, Cytology WCY. Of the progenies derived from hybrid between wheat and octoploid agroticum. Journal of Shanxi. Agric Sci. 2008; 36(2):26-7.

41. Tu Y, Sun J, Ge X, Li Z. Chromosome elimination, addition and introgression in intertribal partial hybrids between Brassica Rapa and Isatis Indigotica. Ann Bot. 2009;103(7):1039-48

42. Tang Z, Fu S, Yan B, Zhang H, Ren Z. Unequal chromosome division and inter-genomic translocation occurred in somatic cells of wheat-rye allopolyploid. J Plant Res. 2012;125(2):283-90.

43. WMRB R. Chromosome studies. I. Taxonomic relationships shown in the chromosomes of Tettegidae and Acrididiae: V-shaped chromosomes and their significance in Acrididae, Locustidae and Grillidae: chromosomes and variations. J Morphol. 1916:27:179-331.

44. Lukaszewski AJ. Behavior of centromeres in univalents and centric misdivision in wheat. Cytogenet Genome Res. 2010;129(1-3):97-109.

45. Guan Q. Formation, meiotic stability and karyotype analysis of octoploid agrotriticum hybrids. Acta Agron Sin. 1980;6(3):129-37.

46. Zhang X, Dong Y, Li Z. Cytogenetic Research on hybrids between Trilicum and Decaploid Thinopyrum ponticum and their derivatives I. Chromosome pairing in Decaploid Th. ponticum and $F_{1}$ hybrids of it with both $T$. aeativum and T. durum. J Genet Genomics. 1993;20(5):439-47.

47. Wu J, Zhao JX, Chen XH, Liu SH, Yang QH, Liu WX, et al. Cytology characteristic and GISH analysis on the progenies derived from common wheat (T.aestivum L.) XPsathyrostachys huashanica. Journal of Triticeae Crops. 2007;27(5):772-5.

48. Dvorak J. Homoeology between Agropyron elongatum chromosomes and Triticum aestivum chromosomes. Can J Genet Cytol. 1980;22(2):237-59.

49. Cai $\mathbf{X}$, Jones S. Direct evidence for high level of autosyndetic pairing in hybrids of Thinopyrum intermedium and Th. ponticum with Triticum aestivum. Theor Appl Genet. 1997;95(4):568-72.

50. Martinezperez E, Shaw P, Moore G. The Ph1 locus is needed to ensure specific somatic and meiotic centromere association. Nature. 2001; 411(6834):204-7.

51. Griffiths S, Sharp R, Foote TN, et al. Molecular characterization of Ph1 as a major chromosome pairing locus in polyploid wheat. Nature. 2006; 439(7077):749-52

52. Feldman M, Levy AA. Allopolyploidy-a shaping force in the evolution of wheat genomes. Cytogenet Genome Res. 2005;109(2):250-8.

\section{Submit your next manuscript to BioMed Central and we will help you at every step:}

- We accept pre-submission inquiries

- Our selector tool helps you to find the most relevant journal

- We provide round the clock customer support

- Convenient online submission

- Thorough peer review

- Inclusion in PubMed and all major indexing services

- Maximum visibility for your research

Submit your manuscript at www.biomedcentral.com/submit

) Biomed Central 